special evaluation, interpretation, or abstraction from the total experience. Brindley discusses the limits of usefulness of class $B$ observations, and ways of improving their status. He then applies this logical apparatus to the analysis of a variety of entoptic phenomena, after-images, contrast phenomena and electric phosphenes (Chapter 5) ; functions involving visual thresholds and adaptation (Chapter $6)$; and colour vision (Chapter 7).

Brindley characterizes this volume in his preface as "a tightly written book, very full of information and for this reason not easy to read from end to end consecutively". This is fair enough, though I should add that it repays handsomely whatever trouble one takes with the reading. A few typographical errors at times make special trouble : in Fig. $2 \cdot 4$ (p. 50), the legend says $155 \mu$ when it means $255 \mu$; and in Fig. $2 \cdot 14$, the legend should read "In $a$, taken at $140 \mu$ from the outer ends of the receptors, a large response is recorded from the inner pipette, but almost none from the outer'".

George WaLd

\section{THE SEPARATION OF ISOTOPES}

\section{Electromagnetic Isotope Separators and Applica- tions of Electromagnetically Enriched Isotopes}

By J. Koch, R. H. V. M. Dawton, M. L. Smith and W. Walcher. Pp. xi +314 . (Amsterdam: NorthHolland Publishing Company, 1958.) 26.50 guilders.

T HE separation of isotopes on a large scale was achieved by several methods during the Second World War as a necessary stage in the manufacture of the atom bomb. Of the various methods employed the electromagnetic separator (calutron), based directly on the mass spectrograph principle, was able to be brought to the production stage earliest. The uranium-235 for both the Alamogordo test explosion and the Hiroshima bomb came from the electromagnetic separators. After the War the far more economical gaseous diffusion process was brought into large-scale production so that the calutron process became redundant for the production of uranium-235.

Nevertheless, the many uses for comparatively small amounts of separated stable isotopes of a wide variety of elements which can be obtained most conveniently from electromagnetic separators has kept an interest in the subject alive, so that many laboratories all over the world have acquired such separators in recent years. The availability of samples of almost pure individual isotopes greatly facilitates the work of the nuclear physicist in working out the details of nuclear interactions, in assigning activities to particular isotopes, and in the investigation of the validity of different nuclear models. It is of importance in spectroscopy where it has enabled the elucidation of the finer details of spectra previously masked by the presence of several isotopes, and where it has made possible the achievement of greatly improved wave-length standards. Such separated isotopes have also been used in solid state physics and in biological studies.

The present work consists mainly of a survey of the construction of such practical separators and of the physical principles of their operation. It also includes a very brief discussion of some of the applications of the enriched isotopes produced by the method. It confines its attention to the calutron type of apparatus so that it is not comprehensive in the discussion of all types, even of electromagnetic separators. There is no discussion, for example, of the omegatron. It is divided into three parts, each of about equal length. The first part, written by J. Koch, is devoted mainly, but not exclusively, to separators developed largely independently of the American experience gained during the Second World War. These were mainly developed after the War, but since the American experience was not declassified until the early 'fifties, independent development was necessary.

The second part, by R. H. V. M. Dawton and M. L. Smith, is mainly devoted to the description of the Harwell separators which were constructed in full knowledge of the American war-time experience. The method of treatment necessarily entails a considerable overlap between these two articles. They are both concerned mainly with technical constructional details rather than physical principles and will therefore have a rather restricted appeal.

The physical principles of the ion-optical systems employed, the high-current sources and the fascinating problems raised by the space-charge neutralization of ion beams are discussed by W. Walcher in the third section, which will be of more general interest. The book should prove of great use for those interested in designing isotope separators while the third section will be of interest to wider circles of physicists.

E. H. S. Burhop

\section{EDUCATING YOUNG NATIONS}

\section{Educating Young Nations}

By W. E. F. Ward. Pp. 194. (London: George Allen and Unwin, Ltd., 1959.) 15s. net.

A MAN who took Beethoven's Fifth Symphony to A the Gold Goast thirty-five years ago, and made that music understood, and who to-day writes of the necessity to foster, through education, common nationhoods, which yet respect cultural diversities, has within him a Greek sense of balance and a Christian humanity. These qualities make Mr. Ward's book memorable, kindly and historical. It will be of political and professional value to administrators and educationists working in the newly independent countries of Africa and Asia which have grown up overnight.

Mr. Ward wrote this book in 1959. It is now past history which will interest the newcomers to the field of public service. To those who shared the experience it will provide nostalgic delight. The validity of the thesis that education, particularly the education of a reserve of good teachers, "everyone of whom will be needed when the day of expansion comes", has already been proved. The plea for European technicians to stand by, while the new nations find their feet, is already the theme of the speeches of the more balanced politicians. The proposal that money for education should be looked upon by governments as aid to development rather than to welfare projects, commanding assistance "as if it were a scheme for irrigating the Sahara" is likely to gain the sympathy of the now Ministries of Finance.

Mr. Ward is probably the last author to write contemporarily of "the Colonies" and of "expansion" as a synonym for "independence". His catholic experience of teaching and administrating in places as dispersed as the old Gold Coast and Mauritius, his representation of the interests of those countries in the 